\title{
HLA-G orchestrates the early interaction of human trophoblasts with the maternal niche
}

\author{
Silvia Gregori ${ }^{1}$ *, Giada Amodio ${ }^{1}$, Federica Quattrone ${ }^{2}$ and Paola Panina-Bordignon ${ }^{2}$. \\ Division of Regenerative Medicine, Stem Cells and Gene Therapy, San Raffaele Telethon Institute for Gene Therapy (HSR-TIGET), IRCCS San Raffaele Scientific \\ Institute, Milan, Italy \\ 2 Reproductive Sciences Laboratory, Division of Genetics and Cell Biology, IRCCS San Raffaele Hospital, Milan, Italy
}

Edited by:

Rachel R. Caspi, National Institutes of Health, USA

\section{Reviewed by:}

Vito Pistoia, Istituto Giannina Gaslini, Italy

Vera Rebmann, University

Duisburg-Essen, Germany

*Correspondence:

Silvia Gregori, Division of

Regenerative Medicine, Stem Cells

and Gene Therapy, San Raffaele

Telethon Institute for Gene Therapy

(HSR-TIGET), IRCCS San Raffaele

Scientific Institute, Via Olgettina, 58,

Milan 20132, Italy

e-mail: gregori.silvia@hsr.it;

Paola Panina-Bordignon, Reproductive

Sciences Laboratory, Division of

Genetics and Cell Biology, IRCCS

San Raffaele Scientific Institute, Via

Olgettina 58, Milan 20132, Italy

e-mail: panina.paola@hsr.it
Extravillous trophoblasts (EVTs) play a central role in educating maternal leukocytes, endometrial stromal and endothelial cells to generate a receptive decidual microenvironment tailored to accept the semi-allogeneic fetus. HLA-G, a non-classical HLA class I molecule endowed with immune-regulatory functions, is primarily expressed on EVTs lining the placenta and on the naturally occurring tolerogenic dendritic cells, named DC10, which are enriched in the human first trimester decidua. Decidual DC-10 are involved in HLA-G-mediated tolerance at the maternal-fetal interface. EVTs not only establish a tolerogenic microenvironment through the interaction with maternal innate and adaptive cells but also orchestrate placenta vascular and tissue remodeling, leading to a successful pregnancy. Here, we discuss the potential implications of the HLA-G-mediated cross-talk among the cells present at the maternal-fetal interface, and its role in maintaining a positive relationship between the mother and the fetus.

Keywords: HLA-G, trophoblasts, dendritic cells, IL-10, T regulatory cells, vascular remodeling

\section{INTRODUCTION}

The maternal-fetal interface is composed of fetal trophoblasts intermingled with maternal leukocytes, stromal, and endothelial cells that comprise the decidua. During implantation, trophoblasts, derived from the trophoectoderm surrounding the blastocyst, differentiate into the syncytiotrophoblasts that infiltrates the endometrium, and the cytotrophoblasts at the embryo side. The layer of syncytiotrophoblasts in contact with the decidua represents the extravillous trophoblasts (EVTs) (Figure 1). EVTs orchestrate bi-directional cross-talk between the mother and the fetus by providing structural and biochemical barriers, serving as an endocrine organ that support and regulate placental and fetal development and growth, and modulating maternal innate and adaptive immune responses (1).

The evidence that, after embryo implantation, defective development and function of EVTs can lead to fetal loss and pregnancyassociated pathological conditions, including pre-eclampsia and intrauterine growth restriction (2-4), sustains the important role of EVTs in orchestrating the decidual modification for successful pregnancy. The expression of HLA-G, a non-classical HLA class I molecule, on EVTs contributes to trophoblast invasiveness, decidual cell differentiation, vascular remodeling, and maintenance of a local immunosuppressive state. A proper understanding of regulatory mechanisms that control EVTs interaction with the maternal niche is a critical issue in reproduction.

\section{STATE OF THE ART}

\section{HORMONAL REGULATION AT THE MATERNAL-FETAL INTERFACE}

The endometrial microenvironment, constituted by luminal and glandular epithelial cells, stromal cells, fibroblasts, vascular smooth muscle cells, endothelial cells, leukocytes, endometrial stem cells, and dynamic leukocyte populations, undergoes cyclical changes regulated by sex hormones. In the absence of pregnancy, the endometrium is sloughed off at menstruation. In the postmenstrual proliferative phase, under estradiol stimulation, it undergoes rapid regeneration into a fertile soil capable to accept the embryo (5). During the secretory phase, the blood flow increases, the arteries branches, and the glands enlarge and start to secrete fluids rich in glycogen used by the embryo as an energy source in its early stages of growth. These processes are driven by the post-ovulatory rise of progesterone that inhibits the proproliferative effect of estradiol and, in mammals, induces a radical transformation of the endometrium (pre-decidualization) that heralds the limited period of endometrial receptivity, ("implantation window") during which embryo attachment can take place (6). Pre-decidualization is primarily defined by the transformation of endometrial stromal cells into secretory epithelioid-like decidua cells and is characterized by massive influx of maternal innate immune cells and vascular remodeling (7).

In the presence of the embryo, the human chorionic gonadotropin (hCG) sustains the full decidualization of the 


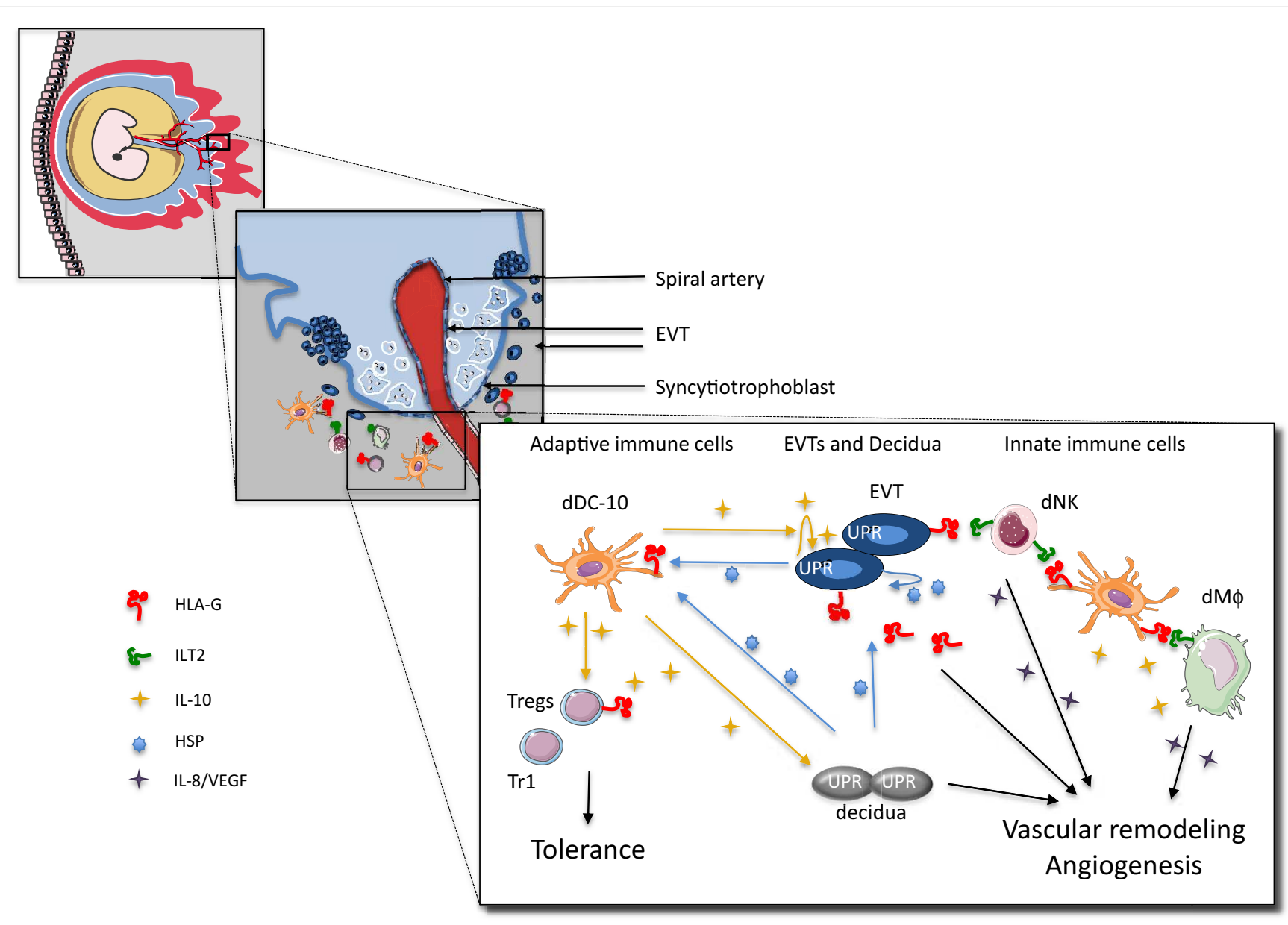

FIGURE 1 | Proposed model for cross-talk among embryo trophoblasts, decidual leukocytes, and stromal cells at the maternal-fetal interface in human first trimester pregnancy. EVTs express and secrete HLA-G, and release IL-10 (and TSLP), which instruct dAPCs to become tolerogenic DC (i.e., dDC-10 or TSLP-modulated dDC) secreting IL-10 and promoting the induction of a variety of Tregs (i.e., $\operatorname{Tr} 1$ cells, CD4 ${ }^{+} \mathrm{CD} 25^{+} \mathrm{FOXP3}^{+}$Tregs, and $\mathrm{CD} 4^{+} \mathrm{HLA}-\mathrm{G}^{+}$Tregs). Induced Tregs inhibit effector $T$ cells, and, via IL-10 secretion, promote HLA-G expression on EVTs. EVTs via HLA-G directly promote dNK cell activation and the release of angiogenic factors. $\mathrm{dDC}-10$ is $\mathrm{HLA}_{-} \mathrm{G}^{+}$and can interact with either $\mathrm{dNKs}$ or $\mathrm{dM} \Phi$ via ILT2, and promote their activation and pro-angiogenic effects. dDC-10 themselves secrete also pro-angiogenic factors supporting neo-vascularization. HSPs secreted by the maternal cells and trophoblasts contribute to the regulation of HLA-G expression on dAPCs and EVTs. Finally, IL-10 modulates the UPR pathway and regulates vascular uterine remodeling by HLA-G ${ }^{+}$EVTs. endometrium via stimulation of progesterone production. hCG is the most specific embryo-derived signal observed in humans and the $h C G$ gene is transcribed as early as the two-cell stage (8, 9). Being released before embryo implantation, hCG also acts on endometrial cells in a paracrine way by inducing their differentiation characterized by secretion of prolactin, leukemia inhibitory factor (LIF), and IL-6 (10, 11). Furthermore, hCG promotes angiogenesis by increasing vessel sprouting of endothelial cells and secretion of vascular endothelial growth factor (VEGF) $(12,13)$. The immunomodulatory properties of hCG are multiple (13): it regulates decidual natural killer $(\mathrm{dNK})$ cell proliferation, contributing to the remodeling of decidual spiral arterioles $(14,15)$; it induces CXCL8 production by monocytes (16); it influences tolerogenic dendritic cells (DCs) proliferation and differentiation (17); and it contributes to recruitment of T regulatory cells (Tregs) (18).
The pre-ovulatory peak of estrogen is important for proliferation of the uterine epithelium in preparation for implantation, while rising progesterone after ovulation is required for implantation of the embryo and decidual differentiation. Together with hCG, progesterone and estradiol are also essential for the programing of a local tolerogenic environment (19). Progesterone polarizes T-cell responses toward an anti-inflammatory phenotype, favoring $\mathrm{T}$ (helper)h2 while dampening Th1 and Th17 cells, and inducing Tregs via thymic stromal lymphopoietin (TSLP) (20-22). The increased concentration of progesterone at the maternal-fetal interface may play a role in regulating HLA-G gene expression (23). Progesterone induces up-regulation of HLA-G in primary cultures of first trimester cytotrophoblasts through the binding to an alternative progesterone response element in the HLA-G promoter (24). 
Estradiol regulates the immune system by affecting $\mathrm{T}$ and $\mathrm{B}$ cells, and down regulating NK cell cytotoxicity (25). Interestingly, estradiol helps to regulate fetal tolerance during pregnancy by expanding Tregs and their suppressive function $(26,27)$.

Dendritic cells, by expressing specific receptors, are susceptible to stimulation with hCG, progesterone, and estradiol. Pregnancy hormones can either activate or reduce the stimulatory activity of monocyte-derived DCs. Consistent up-regulation of IL-10 production by human DCs has been observed upon stimulation with pregnancy hormones [as reviewed in Ref. (28)].

\section{HLA-G-EXPRESSING TROPHOBLAST AT THE MATERNAL-FETAL INTERFACE}

HLA-G has well-recognized immunomodulatory activities, is low polymorphic [reviewed in Ref. (29)], and has limited tissue distribution [reviewed in Ref. (30)]. HLA-G was the first HLA class I molecule identified on EVTs (31). EVTs, forming the placental interface with the maternal systemic circulation, do not express HLA class I, but as they differentiate to invade the decidua and contact maternal decidual leukocytes, they begin to express HLA-G (32). All EVTs, syncytiotrophoblasts (33), interstitial and endovascular trophoblasts, and placental bed giant cells are HLA-G positive [reviewed in Ref. (34)].

By alternative splicing of the primary transcript, four membrane-bound (HLA-G1 to -G4) and three soluble (HLAG5 to -G7) isoforms can be generated [reviewed in Ref. (35)]. In addition, a soluble isoform, named shed HLA-G1, is released after proteolytic cleavage of the membrane-bound HLA-G1 by metalloproteinases $(36,37)$. Through the interaction with the inhibitory receptors immunoglobulin-like transcript (ILT)2 and ILT4, and the killer immunoglobulin-like receptor (KIR)2DL4, HLA-G regulates innate and adaptive immune responses and participates in promoting tolerance [reviewed in Ref. (38)].

During the last decade, it has become evident that the expression of HLA-G on EVTs is not primarily involved in protecting the fetus from the attack by maternal cells, but it plays an important role in tissue remodeling. HLA-G expressed or secreted by EVTs controls their decidual and endovascular invasion. EVTs can express membrane-bound or shed HLA-G1, and soluble HLAG2, -G5, and -G6 (39-43) (Table 1). Studies in placental sections demonstrated that $\beta 2 \mathrm{~m}$-bound HLA-G is expressed by all EVTs, whereas more distal EVTs at the invasion front express the free heavy chain (FHC) HLA-G (40). It has been proposed that the selective expression of FHC-HLA-G, which is not recognized by ILT2 (44), may limit the inhibition of dNKs while allowing these cells to secrete factors required for successful pregnancy. In vitro studies showed that treatment of primary trophoblasts with HLA-G5 stimulates cell invasion and increases the production of metalloproteinases and urokinase, known to remodel the endometrial extracellular matrix $(45,46)$. Moreover, the interaction between HLA-G on EVTs and dNKs leads to CXCL8 and CXCL10 secretion that in turn, via stimulation of CXCR1 and CXCR3, promote EVTs invasiveness (14). Thereby, HLA-Gexpressing EVTs regulate decidual invasion in both autocrine and paracrine manner.

The presence of soluble HLA-G in embryo culture supernatants positively associates with embryo implantation (58-60). The interaction of HLA-G with ILT2 on endometrial stromal cells

Table 1 | Expression pattern of HLA-G-related molecules on cells at the maternal-fetal interface.

\begin{tabular}{|c|c|c|c|c|c|}
\hline \multirow[t]{2}{*}{ Cell types } & & \multirow[t]{2}{*}{ HLA-G isoforms (reference) } & \multicolumn{3}{|c|}{ HLA-G receptors (reference) } \\
\hline & & & ILT2 & ILT4 & KIR2DL4 \\
\hline \multirow[t]{5}{*}{ EVTs } & & HLA-G1 $(39,40)$ & $\operatorname{Neg}(47)$ & $\operatorname{Neg}(47)$ & n.t. \\
\hline & & shed HLA-G1 $(40,42)$ & & & \\
\hline & & HLA-G2 (42) & & & \\
\hline & & HLA-G5 (41) & & & \\
\hline & & HLA-G6 (43) & & & \\
\hline Syncytiotrophoblasts & & HLA-G5 (33) & $\operatorname{Neg}(47)$ & $\operatorname{Neg}(47)$ & n.t. \\
\hline \multirow[t]{2}{*}{ Endothelial cells } & Maternal endothelium & n.t. & $\operatorname{Neg}(47)$ & $\operatorname{Neg}(47)$ & n.t. \\
\hline & Fetal vessels & n.t. & $\operatorname{Neg}(47)$ & n.t. & n.t. \\
\hline Endometrial stromal cells & & n.t. & Pos (47) & Neg (47) & n.t. \\
\hline dNK & Total CD56 ${ }^{+}$ & Neg (48) & Pos low (49) & $\operatorname{Neg}(49)$ & Pos (49-51) \\
\hline \multirow[t]{2}{*}{$\mathrm{CD}^{+}$} & Total CD4 ${ }^{+}$ & n.t. & Pos (52) & n.t. & Pos (52) \\
\hline & $\mathrm{CD}^{+}{ }^{+} \mathrm{HLA}_{-} \mathrm{G}^{+}$ & HLA-G1 $(53,54)$ & n.t. & n.t. & n.t. \\
\hline \multirow[t]{2}{*}{$\mathrm{CD}^{+}$} & Total CD8 ${ }^{+}$ & n.t. & n.t. & n.t. & n.t. \\
\hline & $\mathrm{CD}^{+} \mathrm{HLA}^{-\mathrm{G}^{+}}$ & HLA-G1 (53) & n.t. & n.t. & n.t. \\
\hline Macrophages & $\mathrm{CD}_{14}{ }^{+} \mathrm{CD} 163^{+}$ & Neg (55) & Pos $(50,56)$ & Pos $(50,56)$ & n.t. \\
\hline \multirow[t]{2}{*}{ DCs } & DC-SIGN ${ }^{+}$ & HLA-G1 (57) & n.t. & Pos (57) & n.t. \\
\hline & DC-10 & HLA-G1 (53) & Pos (53) & Pos (53) & n.t. \\
\hline
\end{tabular}

The indicated markers have been tested on cells at the maternal-fetal interface and demonstrated to be expressed (Pos) or not (Neg).

The indicated markers have not been tested yet (n.t.). 
(47) might contribute to the remodeling of uterine vascularization, and EVT migration and invasion $(61,62)$. Moreover, the interaction between EVTs and resident dNKs that express both ILT2, although at low levels, and KIR2DL4 $(49,50)$ guarantees the correct arterial remodeling (Table 1). In contrast to peripheral NK, $\mathrm{dNK}$ are poorly cytotoxic and secrete, in addition to IFN- $\gamma$, the pro-angiogenic factors VEGF, placental growth factor (PLGF), angiopoietin 1 and 2, and transforming growth factor (TGF)$\beta 1$ (14, 63-66). These molecules promote the uterine vascular changes necessary for maximizing maternal blood flow through the placenta. Moreover, the perivascular localization of $\mathrm{dNKs}$ in a microenvironment enriched in EVT-derived soluble HLA-G enables the formation of uterine spiral arteries (67). In vitro studies show that the interaction between HLA-G5 and shed HLA-G1, with KIR2DL4 in the early endosome of activated NKs promotes phenotypical and physiological changes leading to cellular senescence, which sustains the secretion of pro-angiogenic mediators $(49,51)$. Exposure of macrophages $(M \Phi)$ isolated from the first trimester decidua to HLA-G-expressing cell lines induces secretion of IL-6, CXCL8, and TNF- $\alpha$ that activate dNK-mediated vascular remodeling (50). Hence, the cross-talk between HLAG-expressing/secreting EVTs and decidual innate cells coordinate the tissue remodeling necessary for a successful pregnancy.

It cannot be overlooked that EVTs-derived HLA-G also induces tolerogenic immune responses leading to semi-allogeneic fetus acceptance. In addition to $\mathrm{dNKs}, \mathrm{M} \Phi$, DCs, effector and regulatory T cells, and B cells infiltrate the decidua $(52,68,69)$, which are likely to be important determinants in tolerance induction. $\mathrm{dM} \Phi$ are characterized by low levels of CD86 coupled with the expression of the immunomodulatory molecule indoleamine 2,3-dioxigenase (IDO) (70), and by IL-10 production (50, 71, 72). Gene expression profiling demonstrated that $\mathrm{dM} \Phi$ from the first trimester of pregnancy express genes functionally related to immunomodulation and tissue remodeling (73). In vitro studies showed that exposure of U937 cells to HLA-G5 or HLA-G6 modulates IL10 and TGF- $\beta$ secretion (74). Based on these data, and on the fact that $\operatorname{dM} \Phi$ express ILT2 and ILT4 $(50,56)$ (Table 1), it was postulated that, in the presence of dNK-derived IFN- $\gamma, \mathrm{dM} \Phi$ in contact with HLA-G ${ }^{+}$EVTs and exposed to soluble HLA-G are induced to secrete IL-10 and TGF- $\beta$, which limit T-cell responses and promotes tolerance (74).

Plasmacytoid (BDCA-2 ${ }^{+}$) and myeloid (BDCA- ${ }^{+}$and BDCA$\left.3^{+}\right)$DCs have been also identified at the maternal-fetal interface $(53,75,76)$. In early human pregnancy, DC-SIGN ${ }^{+}$dDCs, characterized by low expression of CD86 and DEC-205, were described (77). DC-SIGN ${ }^{+}$dDCs might be involved in re-programing the local immune response since they are associated with GM-CSFand IL-10-secreting large granular lymphocytes that inhibit their maturation, and possibly favor tolerogenic responses (78). It has been shown that a population resembling DC-SIGN ${ }^{+} \mathrm{dDCs}$ that express ILT4 can be differentiated in vitro $(57,76)$, suggesting that these cells can be also modulated by HLA-G ${ }^{+}$decidual resident cells (Table 1). Our group identified a peculiar subset of tolerogenic DCs at the maternal-fetal interface in the first trimester of pregnancy. These DCs, termed DC-10, express HLA-G and ILT4 and secrete IL-10, thus are potentially involved in promoting tolerance (53) (Table 1). Future investigation is warranted to define whether $\mathrm{dDC}-10$ and $\mathrm{DC}-\mathrm{SIGN}{ }^{+} \mathrm{dDCs}$ are distinct populations of tolerogenic APCs, or cells at different stages of differentiation.

It is not surprising that Tregs are present in the decidua during pregnancy. An increased frequency of $\mathrm{CD} 4^{+} \mathrm{FOXP}^{+}$Tregs in the peripheral blood of pregnant women has been shown (79) and the accrual of these cells has been described in human decidua with controversial results $(53,76,80,81)$. Recent evidence indicated that $\mathrm{CD}^{+}{ }^{+} \mathrm{FOXP}^{+}$Tregs might be generated in situ (57). A population of $\mathrm{CD}^{+}{ }^{+} \mathrm{T}$ cells expressing HLA-G, termed CD4 ${ }^{+} \mathrm{HLA}_{-\mathrm{G}}{ }^{+}$ T cells, representing up to $20 \%$ of the decidua-infiltrating $\mathrm{CD}^{+}$ cells, have been recently reported $(53,54)$ (Table $\mathbf{1})$.

\section{OPEN ISSUES \\ TROPHOBLAST-MATERNAL APCs CROSS-TALK: ROLE OF HLA-G-MEDIATED SIGNALS}

For the acceptance of the semi-allogeneic fetus, a crucial role is played by the trophoblasts themselves. In addition to express/secrete HLA-G, EVTs release immune-modulatory mediators (i.e., IL-10 and TSLP), which are involved in promoting a pro-tolerogenic microenvironment. Our group characterized the tolerogenic DC-10 that are present in vivo and are inducible in vitro in the presence of IL-10. DC-10 are mature myeloid cells that spontaneously secrete IL-10 in the absence of IL-12, and express HLA-G, ILT2, ILT3, and ILT4. Importantly, DC-10 promote the induction of adaptive T regulatory type $1(\operatorname{Tr} 1)$ cells via the IL-10induced HLA-G/ILT4 pathway (82). Later, we demonstrated that DC-10 accumulate in human decidua during the first trimester of pregnancy (53). Based on this observation, we postulate that dDC10 may represent the naturally occurring HLA-G-expressing DCs involved in re-programing the immune response toward tolerance. The recent observation that the frequency of $\mathrm{dDC}-10$ in women with spontaneous abortion is lower compared to that observed in pregnant women sustains this hypothesis (our unpublished data). One of the important questions regarding $\mathrm{dDC}-10$ is whether they are recruited in decidua during pregnancy or are induced in situ. Recently, it was demonstrated that the secretion of TSLP by EVTs induces $\mathrm{CD} 11 \mathrm{c}^{+} \mathrm{dDC}$ to express co-stimulatory molecules and HLA-DR and to secrete IL-10 and TGF- $\beta$ (83). TSLP-instructed DCs via TFG- $\beta$ secretion induce $\mathrm{CD} 4{ }^{+} \mathrm{CD} 25^{+}$FOXP $3{ }^{+}$Tregs that inhibit effector T cells, and promote HLA-G expression on EVTs (83). Thus, the decidual microenvironment, enriched in TSLP and IL-10, produced by both EVTs and immune cells, sustains the expression of HLA-G on EVTs. In this scenario, the crosstalk between HLA-G-expressing EVTs and decidual myeloid cells might favor the generation of a set of tolerogenic DCs, including dDC-10 and TSLP-modulated CD11 ${ }^{+}$dDCs, which co-operate in promoting tolerance via the generation of different subsets of Tregs: $\operatorname{Tr} 1, \mathrm{CD} 4{ }^{+} \mathrm{CD} 25^{+} \mathrm{FOXP}^{+}$, or $\mathrm{CD} 4{ }^{+} \mathrm{HLA}_{-} \mathrm{G}^{+}$cells. As discussed above, EVT-derived HLA-G directs $\mathrm{dM} \Phi$ toward a tolerogenic path, which contributes to the inhibition of effector $\mathrm{T}$ cells and to the induction of Tregs. The hypothesis that decidual tolerogenic APCs drive the differentiation of Tregs is supported by the higher frequency of peripherally induced Tregs (defined as Helios ${ }^{-}$ iTreg) compared to the thymic-derived Tregs in decidua (57). Our group recently demonstrated that co-expression of CD49b and LAG-3 identified Tr1 cells in vivo (84); thus, the use of these biomarkers in conjunction with the expression of FOXP3, 
Helios, and HLA-G will better define Treg cell composition at the maternal-fetal interface and define their relationship and relative contribution in tolerance induction.

Tolerogenic DCs can also contribute to sustain the proangiogenic milieu in the decidua. dDC-10 through the HLA-G can interact with $\mathrm{dNKs}$ or $\mathrm{dM} \Phi$ via ILT2 and promote their activation and the release of the angiogenic factors. Moreover, $\mathrm{dDC}-10$ themselves secrete IL-8 and VEGF (our unpublished data), supporting their pro-angiogenic functions. Since $\mathrm{dM} \Phi, \mathrm{dDC}-10$, and TSLP-modulated CD $11 \mathrm{c}^{+} \mathrm{dDC}$ are characterized by the ability to secrete IL-10, they can also support the up-regulation of HLA-G on EVTs and on other decidual infiltrating cells (85), hence facilitating the establishment of an appropriate vascular bed at the maternal-fetal interface.

\section{TROPHOBLAST-DECIDUA CROSS-TALK: ROLE OF HLA-G-MEDIATED SIGNALS}

The pre-decidualization program entails the production of a plethora of transcription factors, cell cycle regulators, cytokines, and the activation of diverse signaling pathways (86). Full decidualization is then achieved upon embryo arrival. In view of the increased requirements for protein secretion during embryo implantation, cytoplasmic and endoplasmic reticulum (ER) stress responses are activated at the maternal-fetal interface. Cytoplasmic stress responses are characterized by the rapid stress-induced synthesis of heat shock proteins (HSPs) that allow cells to restore protein homeostasis and to be protected against molecular damage (87). Stress-induced HSPs are not only essential for regulating the state of intracellular folding, assembly, and translocation of proteins but are also potent modulators of the immune responses. Moreover, HSPs are necessary for placental development. Targeted deletion of HSP90 results in embryonic lethality (88). In primary decidualizing, endometrial stromal cells treated with embryo supernatants, genome wide expression profiling revealed that HSP70 was strongly increased (89).

The range of functions attributed to HSPs has expanded to encompass functions outside the cell (90). Extracellular HSPs may be able to play a role as danger signals (91). In this context, HSPs may interact with pattern recognition receptors, and activate pro-inflammatory signaling and transcription. Specifically, extracellular HSP60 was shown to allow communication between immune cells and other cells in the body (92), and HSP70 can be released from cells after acute stress in different cells, including cultured rat embryo cells (93), and peripheral blood mononuclear cells (94). Notably, HSPs can activate NKs and Tregs (95, 96). Evidence for regulation of HLA-G by HSPs is still scanty. $H L A-G$ transcription was found to be induced upon heat shock in tumor cell lines, by heat shock transcription factor 1 (HSF1) binding to a heat shock element (HSE) present in HLA-G but not in other HLA class I genes (97). Moreover, mice mutant for Hsf1 have a thin spongiotrophoblast layer and die in utero (98). Further investigation is warranted to define if maternal/fetal-derived HSPs might contribute to the regulation of HLA-G expression on dDC-10 and EVTs.

Protein folding in the ER is essential to ensure normal cell function. Disruption of ER homeostasis causes accumulation of misfolded proteins in the ER, a condition referred to as ER stress.
ER stress activates the unfolded protein response (UPR) to restore protein homeostasis within the ER. However, if ER stress is persistent and excessive, the ER homeostasis cannot be re-established and the UPR will induce apoptosis. Intriguingly, IL-10 is emerging as a novel modulator of the ER stress (99). Intestinal epithelial cells isolated from IL-10 $10^{-1}$ mice exhibit increased expression levels of BiP, a prototypic marker for ER stress, suggestive of an increased ER stress in the absence of IL-10. Further observations revealed that IL-10 attenuates tunicamycin-induced ER stress through suppression of $\mathrm{BiP}(100)$. These studies consistently suggest a novel role for IL-10 in modulating ER stress (101). Under ER stress, which occurs during normal development of labyrinthine trophoblasts in the mouse placenta, transcriptional regulation of VEGF is mediated by the three master regulators of the UPR: IRE1a, PERK, and ATF6 (102). The modulation of the UPR pathway by IL-10, produced by $\mathrm{dM} \Phi, \mathrm{dDC}-10$, and TSLP-modulated CD11c ${ }^{+} \mathrm{dDCs}$, might represent an additional mechanism to regulate vascular uterine remodeling and placentation.

\section{PERSPECTIVES}

The existence of mechanisms by which fetal and maternal cells simultaneously attract and modulate each other is intriguing. Upon blastocyst implantation into the uterine wall, trophoblasts differentiate into EVTs that possess the ability to coordinate the cross-talk at the interface via the expression of HLA-G. Accumulating evidence indicate that EVTs play a key role in orchestrating a number of molecular and cellular decidual modifications by (i) regulating cell-migration in the decidua, (ii) supporting the induction of the pro-angiogenic decidual microenvironment necessary for effective vascular remodeling, (iii) inhibiting effector innate and adaptive immune responses, and (iv) promoting a tolerogenic loop in which resident cells are instructed to become tolerogenic. These functions are regulated through the finely tuned specific interactions of HLA-G-expressing EVTs with maternal innate immune cells, adaptive immune cells, and non-immune cells (Figure 1). The interplay among these cells supports the development of an appropriate maternal-fetal niche. Pregnancy hormones are essential to fully support the niche, although their role in regulating HLA-G expression has not been investigated yet (29).

We suggest that the integration and exchange between fetal and maternal blood vessels at the interface is likely to be contributed by multiple mechanisms, including trophoblast interaction with $\mathrm{dNKs}$ and resident/recruited APCs, as well as by the IL-10-driven tolerance and regulation of the UPR pathway in decidual and trophoblast cells.

\section{ACKNOWLEDGMENTS}

This work was supported by Telethon Italy grant number TGT11E02, by the Italian Ministry of Health, RF-2011-02346774, by the European grant for European cooperation in science and technology (Action to Focus and Accelerate Cell-based Toleranceinducing Therapies), and by the Fondazione Giorgio Pardi, Milan, Italy.

\section{REFERENCES}

1. Moffett A, Loke C. Immunology of placentation in eutherian mammals. Nat Rev Immunol (2006) 6(8):584-94. doi:10.1038/nri1897 
2. Rossant J, Cross JC. Placental development: lessons from mouse mutants. Nat Rev Genet (2001) 2(7):538-48. doi:10.1038/35080570

3. Redman CW, Sargent IL. Latest advances in understanding preeclampsia. Science (2005) 308(5728):1592-4. doi:10.1126/science.1111726

4. Pfeffer PL, Pearton DJ. Trophoblast development. Reproduction (2012) 143(3):231-46. doi:10.1530/REP-11-0374

5. Jabbour HN, Kelly RW, Fraser HM, Critchley HO. Endocrine regulation of menstruation. Endocr Rev (2006) 27(1):17-46. doi:10.1210/er.2004-0021

6. Harper MJ. The implantation window. Baillieres Clin Obstet Gynaecol (1992) 6(2):351-71. doi:10.1016/S0950-3552(05)80092-6

7. Brosens JJ, Parker MG, McIndoe A, Pijnenborg R, Brosens IA. A role for menstruation in preconditioning the uterus for successful pregnancy. Am J Obstet Gynecol (2009) 200(6):e1-6. doi:10.1016/j.ajog.2008.11.037

8. Fishel SB, Edwards RG, Evans CJ. Human chorionic gonadotropin secreted by preimplantation embryos cultured in vitro. Science (1984) 223(4638):816-8. doi:10.1126/science.6546453

9. Jurisicova A, Antenos M, Kapasi K, Meriano J, Casper RF. Variability in the expression of trophectodermal markers beta-human chorionic gonadotrophin, human leukocyte antigen-G and pregnancy specific beta-1 glycoprotein by the human blastocyst. Hum Reprod (1999) 14(7):1852-8. doi:10.1093/humrep/14. 7.1852

10. Han SW, Lei ZM, Rao CV. Treatment of human endometrial stromal cells with chorionic gonadotropin promotes their morphological and functional differentiation into decidua. Mol Cell Endocrinol (1999) 147(1-2):7-16. doi:10.1016/ S0303-7207(98)00240-8

11. Perrier d'Hauterive S, Charlet-Renard C, Berndt S, Dubois M, Munaut C, Goffin $\mathrm{F}$, et al. Human chorionic gonadotropin and growth factors at the embryonicendometrial interface control leukemia inhibitory factor (LIF) and interleukin 6 (IL-6) secretion by human endometrial epithelium. Hum Reprod (2004) 19(11):2633-43. doi:10.1093/humrep/deh450

12. Berndt S, Perrier d'Hauterive S, Blacher S, Pequeux C, Lorquet S, Munaut C, et al. Angiogenic activity of human chorionic gonadotropin through LH receptor activation on endothelial and epithelial cells of the endometrium. FASEB J (2006) 20(14):2630-2. doi:10.1096/fj.06-5885fje

13. Tsampalas M, Gridelet V, Berndt S, Foidart JM, Geenen V, Perrier d'Hauterive S. Human chorionic gonadotropin: a hormone with immunological and angiogenic properties. J Reprod Immunol (2010) 85(1):93-8. doi:10.1016/j.jri.2009. 11.008

14. Hanna J, Goldman-Wohl D, Hamani Y, Avraham I, Greenfield C, NatansonYaron S, et al. Decidual NK cells regulate key developmental processes at the human fetal-maternal interface. Nat Med (2006) 12(9):1065-74. doi:10.1038/ $\mathrm{nm} 1452$

15. Moffett A, Colucci F. Uterine NK cells: active regulators at the maternal-fetal interface. J Clin Invest (2014) 124(5):1872-9. doi:10.1172/JCI68107

16. Kosaka K, Fujiwara H, Tatsumi K, Yoshioka S, Sato Y, Egawa H, et al. Human chorionic gonadotropin (HCG) activates monocytes to produce interleukin-8 via a different pathway from luteinizing hormone/HCG receptor system. J Clin Endocrinol Metab (2002) 87(11):5199-208. doi:10.1210/jc.2002-020341

17. Wan H, Versnel MA, Leijten LM, van Helden-Meeuwsen CG, Fekkes D, Leenen $\mathrm{PJ}$, et al. Chorionic gonadotropin induces dendritic cells to express a tolerogenic phenotype. J Leukoc Biol (2008) 83(4):894-901. doi:10.1189/jlb.0407258

18. Schumacher A, Brachwitz N, Sohr S, Engeland K, Langwisch S, Dolaptchieva $\mathrm{M}$, et al. Human chorionic gonadotropin attracts regulatory $\mathrm{T}$ cells into the fetal-maternal interface during early human pregnancy. J Immunol (2009) 182(9):5488-97. doi:10.4049/jimmunol.0803177

19. Siiteri PK, Febres F, Clemens LE, Chang RJ, Gondos B, Stites D. Progesterone and maintenance of pregnancy: is progesterone nature's immunosuppressant? Ann N Y Acad Sci (1977) 286:384-97. doi:10.1111/j.1749-6632.1977.tb29431.x

20. Szekeres-Bartho J, Halasz M, Palkovics T. Progesterone in pregnancy; receptorligand interaction and signaling pathways. J Reprod Immunol (2009) 83(12):60-4. doi:10.1016/j.jri.2009.06.262

21. Xu L, Dong B, Wang H, Zeng Z, Liu W, Chen N, et al. Progesterone suppresses Th17 cell responses, and enhances the development of regulatory $\mathrm{T}$ cells, through thymic stromal lymphopoietin-dependent mechanisms in experimental gonococcal genital tract infection. Microbes Infect (2013) 15(12):796-805. doi:10.1016/j.micinf.2013.06.012

22. Mao G, Wang J, Kang Y, Tai P, Wen J, Zou Q, et al. Progesterone increases systemic and local uterine proportions of CD4+CD25+ Treg cells during midterm pregnancy in mice. Endocrinology (2010) 151(11):5477-88. doi:10.1210/en. 2010-0426

23. Halasz M, Szekeres-Bartho J. The role of progesterone in implantation and trophoblast invasion. J Reprod Immunol (2013) 97(1):43-50. doi:10.1016/j.jri. 2012.10.011

24. Yie SM, Li LH, Li GM, Xiao R, Librach CL. Progesterone enhances HLA-G gene expression in JEG-3 choriocarcinoma cells and human cytotrophoblasts in vitro. Hum Reprod (2006) 21(1):46-51. doi:10.1093/humrep/dei305

25. Nadkarni S, McArthur S. Oestrogen and immunomodulation: new mechanisms that impact on peripheral and central immunity. Curr Opin Pharmacol (2013) 13(4):576-81. doi:10.1016/j.coph.2013.05.007

26. Polanczyk MJ, Carson BD, Subramanian S, Afentoulis M, Vandenbark AA, Ziegler SF, et al. Cutting edge: estrogen drives expansion of the CD4+CD25+ regulatory $\mathrm{T}$ cell compartment. J Immunol (2004) 173(4):2227-30. doi:10. 4049/jimmunol.173.4.2227

27. Polanczyk MJ, Hopke C, Huan J, Vandenbark AA, Offner H. Enhanced FoxP3 expression and Treg cell function in pregnant and estrogen-treated mice. J Neuroimmunol (2005) 170(1-2):85-92. doi:10.1016/j.jneuroim.2005.08.023

28. Schumacher A, Costa SD, Zenclussen AC. Endocrine factors modulating immune responses in pregnancy. Front Immunol (2014) 5:196. doi:10.3389/ fimmu.2014.00196

29. Castelli EC, Veiga-Castelli LC, Yaghi L, Moreau P, Donadi EA. Transcriptional and posttranscriptional regulations of the HLA-G gene. J Immunol Res (2014) 2014:734068. doi:10.1155/2014/734068

30. Curigliano G, Criscitiello C, Gelao L, Goldhirsch A. Molecular pathways: human leukocyte antigen G (HLA-G). Clin Cancer Res (2013) 19(20):5564-71. doi:10.1158/1078-0432.CCR-12-3697

31. Ellis SA, Sargent IL, Redman CW, McMichael AJ. Evidence for a novel HLA antigen found on human extravillous trophoblast and a choriocarcinoma cell line. Immunology (1986) 59(4):595-601.

32. Loke YW, King A, Burrows TD. Decidua in human implantation. Hum Reprod (1995) 10(Suppl 2):14-21. doi:10.1093/humrep/10.suppl_2.14

33. Ishitani A, Sageshima N, Lee N, Dorofeeva N, Hatake K, Marquardt H, et al. Protein expression and peptide binding suggest unique and interacting functional roles for HLA-E, F, and G in maternal-placental immune recognition. J Immunol (2003) 171(3):1376-84. doi:10.4049/jimmunol.171.3.1376

34. Apps R, Gardner L, Moffett A. A critical look at HLA-G. Trends Immunol (2008) 29(7):313-21. doi:10.1016/j.it.2008.02.012

35. Carosella ED, Moreau P, Lemaoult J, Rouas-Freiss N. HLA-G: from biology to clinical benefits. Trends Immunol (2008) 29(3):125-32. doi:10.1016/j.it.2007. 11.005

36. Dong Y, Lieskovska J, Kedrin D, Porcelli S, Mandelboim O, Bushkin Y. Soluble nonclassical HLA generated by the metalloproteinase pathway. Hum Immunol (2003) 64(8):802-10. doi:10.1016/S0198-8859(03)00093-4

37. Rizzo R, Trentini A, Bortolotti D, Manfrinato MC, Rotola A, Castellazzi M, et al. Matrix metalloproteinase-2 (MMP-2) generates soluble HLA-G1 by cell surface proteolytic shedding. Mol Cell Biochem (2013) 381(1-2):243-55. doi:10.1007/s11010-013-1708-5

38. Amodio G, Sales de Albuquerque R, Gregori S. New insights into HLA-G mediated tolerance. Tissue Antigens (2014) 84(3):255-63. doi:10.1111/tan.12427

39. Kovats S, Main EK, Librach C, Stubblebine M, Fisher SJ, DeMars R. A class I antigen, HLA-G, expressed in human trophoblasts. Science (1990) 248(4952):220-3. doi:10.1126/science. 2326636

40. Gonen-Gross T, Goldman-Wohl D, Huppertz B, Lankry D, Greenfield C, Natanson-Yaron S, et al. Inhibitory NK receptor recognition of HLA-G: regulation by contact residues and by cell specific expression at the fetalmaternal interface. PLoS One (2010) 5(1):e8941. doi:10.1371/journal.pone. 0008941

41. Morales PJ, Pace JL, Platt JS, Langat DK, Hunt JS. Synthesis of beta(2)microglobulin-free, disulphide-linked HLA-G5 homodimers in human placental villous cytotrophoblast cells. Immunology (2007) 122(2):179-88. doi: 10.1111/j.1365-2567.2007.02623.x

42. Morales PJ, Pace JL, Platt JS, Phillips TA, Morgan K, Fazleabas AT, et al. Placental cell expression of HLA-G2 isoforms is limited to the invasive trophoblast phenotype. J Immunol (2003) 171(11):6215-24. doi:10.4049/jimmunol.171. 11.6215

43. Hunt JS, Petroff MG, McIntire RH, Ober C. HLA-G and immune tolerance in pregnancy. FASEB J (2005) 19(7):681-93. doi:10.1096/fj.04-2078rev 
44. Gonen-Gross T, Achdout H, Arnon TI, Gazit R, Stern N, Horejsi V, et al. The CD85J/leukocyte inhibitory receptor-1 distinguishes between conformed and beta 2-microglobulin-free HLA-G molecules. J Immunol (2005) 175(8):4866-74. doi:10.4049/jimmunol.175.8.4866

45. Bai SX, Wang YL, Qin L, Xiao ZJ, Herva R, Piao YS. Dynamic expression of matrix metalloproteinases (MMP-2, -9 and -14) and the tissue inhibitors of MMPs (TIMP-1, -2 and -3 ) at the implantation site during tubal pregnancy. Reproduction (2005) 129(1):103-13. doi:10.1530/rep.1.00283

46. Guo Y, Lee CL, So KH, Gao J, Yeung WS, Yao Y, et al. Soluble human leukocyte antigen-g5 activates extracellular signal-regulated protein kinase signaling and stimulates trophoblast invasion. PLoS One (2013) 8(10):e76023. doi:10.1371/journal.pone.0076023

47. McIntire RH, Sifers T, Platt JS, Ganacias KG, Langat DK, Hunt JS. Novel HLAG-binding leukocyte immunoglobulin-like receptor (LILR) expression patterns in human placentas and umbilical cords. Placenta (2008) 29(7):631-8. doi:10.1016/j.placenta.2008.04.007

48. Rouas-Freiss N, Goncalves RM, Menier C, Dausset J, Carosella ED. Direct evidence to support the role of HLA-G in protecting the fetus from maternal uterine natural killer cytolysis. Proc Natl Acad Sci U S A (1997) 94(21):11520-5. doi:10.1073/pnas.94.21.11520

49. Rajagopalan S, Bryceson YT, Kuppusamy SP, Geraghty DE, van der Meer A, Joosten I, et al. Activation of NK cells by an endocytosed receptor for soluble HLA-G. PLoS Biol (2006) 4(1):e9. doi:10.1371/journal.pbio.0040009

50. Li CHB, Nicotra ML, Strominger JL. HLA-G homodimer-induced cytokine secretion through HLA-G receptors on human decidual macrophages and natural killer cells. Proc Natl Acad Sci U S A (2009) 106(14):5767-72. doi:10.1073/pnas.0901173106

51. Rajagopalan S, Long EO. Cellular senescence induced by CD158d reprograms natural killer cells to promote vascular remodelling. Proc Natl Acad Sci U S A (2012) 109(50):20596-601. doi:10.1073/pnas.1208248109

52. Lombardelli L, Aguerre-Girr M, Logiodice F, Kullolli O, Casart Y, Polgar B, et al. HLA-G5 induces IL-4 secretion critical for successful pregnancy through differential expression of ILT2 receptor on decidual CD4(+) T cells and macrophages. J Immunol (2013) 191(7):3651-62. doi:10.4049/jimmunol.1300567

53. Amodio G, Mugione A, Sanchez AM, Vigano P, Candiani M, Somigliana E, et al. HLA-G expressing DC-10 and CD4(+) T cells accumulate in human decidua during pregnancy. Hum Immunol (2013) 74(4):406-11. doi:10.1016/ j.humimm.2012.11.031

54. Hsu P, Santner-Nanan B, Joung S, Peek MJ, Nanan R. Expansion of CD4(+) HLA-G(+) T cell in human pregnancy is impaired in pre-eclampsia. Am J Reprod Immunol (2014) 71(3):217-28. doi:10.1111/aji.12195

55. Sedlmayr P, Morales P, Trummer S, Wascher K, Azzola D, Blaschitz A, et al. Absence of HLA-G expression in macrophages of human decidua. Am J Reprod Immunol (2002) 48(2):96-102. doi:10.1034/j.1600-0897.2002.01116.x

56. Petroff MG, Sedlmayr P, Azzola D, Hunt JS. Decidual macrophages are potentially susceptible to inhibition by class Ia and class Ib HLA molecules. J Reprod Immunol (2002) 56(1-2):3-17. doi:10.1016/S0165-0378(02)00024-4

57. Hsu P, Santner-Nanan B, Dahlstrom JE, Fadia M, Chandra A, Peek M, et al. Altered decidual DC-SIGN+ antigen-presenting cells and impaired regulatory T-cell induction in preeclampsia. Am J Pathol (2012) 181(6):2149-60. doi:10.1016/j.ajpath.2012.08.032

58. Fuzzi B, Rizzo R, Criscuoli L, Noci I, Melchiorri L, Scarselli B, et al. HLA$\mathrm{G}$ expression in early embryos is a fundamental prerequisite for the obtainment of pregnancy. Eur J Immunol (2002) 32(2):311-5. doi:10.1002/15214141(200202)32:2<311::AID-IMMU311>3.0.CO;2-8

59. Noci I, Fuzzi B, Rizzo R, Melchiorri L, Criscuoli L, Dabizzi S, et al. Embryonic soluble HLA-G as a marker of developmental potential in embryos. Hum Reprod (2005) 20(1):138-46. doi:10.1093/humrep/deh572

60. Rebmann V, Switala M, Eue I, Grosse-Wilde H. Soluble HLA-G is an independent factor for the prediction of pregnancy outcome after ART: a German multi-centre study. Hum Reprod (2010) 25(7):1691-8. doi:10.1093/humrep/ deq120

61. Das P, Ezashi T, Schulz LC, Westfall SD, Livingston KA, Roberts RM. Effects of fgf2 and oxygen in the bmp4-driven differentiation of trophoblast from human embryonic stem cells. Stem Cell Res (2007) 1(1):61-74. doi:10.1016/j.scr.2007. 09.004

62. Rizzo R, Vercammen M, van de Velde H, Horn PA, Rebmann V. The importance of HLA-G expression in embryos, trophoblast cells, and embryonic stem cells. Cell Mol Life Sci (2011) 68(3):341-52. doi:10.1007/s00018-010-0578-1
63. Koopman LA, Kopcow HD, Rybalov B, Boyson JE, Orange JS, Schatz F, et al. Human decidual natural killer cells are a unique NK cell subset with immunomodulatory potential. J Exp Med (2003) 198(8):1201-12. doi:10.1084/ jem.20030305

64. Kopcow HDAD, Chen X, Rybalov B, Andzelm MM, Ge B, Strominger JL. Human decidual NK cells form immature activating synapses and are not cytotoxic. Proc Natl Acad Sci U S A (2005) 102(43):15563-8. doi:10.1073/pnas. 0507835102

65. Lash GE, Robson SC, Bulmer JN. Review: functional role of uterine natural killer (uNK) cells in human early pregnancy decidua. Placenta (2010) 31(Suppl):S87-92. doi:10.1016/j.placenta.2009.12.022

66. Cerdeira AS, Rajakumar A, Royle CM, Lo A, Husain Z, Thadhani RI, et al. Conversion of peripheral blood NK cells to a decidual NK-like phenotype by a cocktail of defined factors. J Immunol (2013) 190(8):3939-48. doi:10.4049/jimmunol.1202582

67. Bulmer JN, Lash GE. Human uterine natural killer cells: a reappraisal. Mol Immunol (2005) 42(4):511-21. doi:10.1016/j.molimm.2004.07.035

68. Kammerer U, Eggert AO, Kapp M, McLellan AD, Geijtenbeek TB, Dietl J, et al. Unique appearance of proliferating antigen-presenting cells expressing DCSIGN (CD209) in the decidua of early human pregnancy. Am J Pathol (2003) 162(3):887-96. doi:10.1016/S0002-9440(10)63884-9

69. Plaks V, Birnberg T, Berkutzki T, Sela S, BenYashar A, Kalchenko V, et al. Uterine DCs are crucial for decidua formation during embryo implantation in mice. J Clin Invest (2008) 118(12):3954-65. doi:10.1172/JCI36682

70. Heikkinen J, Mottonen M, Komi J, Alanen A, Lassila O. Phenotypic characterization of human decidual macrophages. Clin Exp Immunol (2003) 131(3):498-505. doi:10.1046/j.1365-2249.2003.02092.x

71. McIntire RH, Ganacias KG, Hunt JS. Programming of human monocytes by the uteroplacental environment. Reprod Sci (2008) 15(5):437-47. doi:10.1177/ 1933719107314065

72. Hunt JS, Petroff MG. IFPA senior award lecture: reproductive immunology in perspective - reprogramming at the maternal-fetal interface. Placenta (2013) 34(Suppl):S52-5. doi:10.1016/j.placenta.2012.12.005

73. Gustafsson C, Mjosberg J, Matussek A, Geffers R, Matthiesen L, Berg G, et al. Gene expression profiling of human decidual macrophages: evidence for immunosuppressive phenotype. PLoS One (2008) 3(4):e2078. doi:10.1371/ journal.pone.0002078

74. McIntire RH, Morales PJ, Petroff MG, Colonna M, Hunt JS. Recombinant HLA-G5 and -G6 drive U937 myelomonocytic cell production of TGF-beta1. J Leukoc Biol (2004) 76(6):1220-8. doi:10.1189/jlb.0604337

75. Ban YL, Kong BH, Qu X, Yang QF, Ma YY. BDCA-1+, BDCA-2+ and BDCA-3+ dendritic cells in early human pregnancy decidua. Clin Exp Immunol (2008) 151(3):399-406. doi:10.1111/j.1365-2249.2007.03576.x

76. Hsu P, Nanan RK. Innate and adaptive immune interactions at the fetalmaternal interface in healthy human pregnancy and pre-eclampsia. Front Immunol (2014) 5:125. doi:10.3389/fimmu.2014.00125

77. Blois SM, Alba Soto CD, Tometten M, Klapp BF, Margni RA, Arck PC. Lineage, maturity, and phenotype of uterine murine dendritic cells throughout gestation indicate a protective role in maintaining pregnancy. Biol Reprod (2004) 70(4):1018-23. doi:10.1095/biolreprod.103.022640

78. Laskarin G, Kammerer U, Rukavina D, Thomson AW, Fernandez N, Blois SM. Antigen-presenting cells and materno-fetal tolerance: an emerging role for dendritic cells. Am J Reprod Immunol (2007) 58(3):255-67. doi:10.1111/j.16000897.2007.00511.x

79. Schumacher A, Zenclussen AC. Regulatory T cells: regulators of life. Am J Reprod Immunol (2014) 72(2):158-70. doi:10.1111/aji.12238

80. Mjosberg J, Berg G, Jenmalm MC, Ernerudh J. FOXP3+ regulatory T cells and T helper 1, T helper 2, and T helper 17 cells in human early pregnancy decidua. Biol Reprod (2010) 82(4):698-705. doi:10.1095/biolreprod.109.081208

81. Somerset DA, Zheng Y, Kilby MD, Sansom DM, Drayson MT. Normal human pregnancy is associated with an elevation in the immune suppressive CD25+ CD4+ regulatory T-cell subset. Immunology (2004) 112(1):38-43. doi:10.1111/j.1365-2567.2004.01869.x

82. Gregori S, Tomasoni D, Pacciani V, Scirpoli M, Battaglia M, Magnani CF, et al. Differentiation of type 1 T regulatory cells $(\operatorname{Tr} 1)$ by tolerogenic DC-10 requires the IL-10-dependent ILT4/HLA-G pathway. Blood (2010) 116(6):935-44. doi:10.1182/blood-2009-07-234872

83. Du MR, Guo PF, Piao HL, Wang SC, Sun C, Jin LP, et al. Embryonic trophoblasts induce decidual regulatory $\mathrm{T}$ cell differentiation and maternal-fetal tolerance 
through thymic stromal lymphopoietin instructing dendritic cells. J Immunol (2014) 192(4):1502-11. doi:10.4049/jimmunol.1203425

84. Gagliani N, Magnani CF, Huber S, Gianolini ME, Pala M, Licona-Limon P, et al. Coexpression of CD49b and LAG-3 identifies human and mouse T regulatory type 1 cells. Nat Med (2013) 19(6):739-46. doi:10.1038/nm.3179

85. Moreau P, Adrian-Cabestre F, Menier C, Guiard V, Gourand L, Dausset J, et al. IL-10 selectively induces HLA-G expression in human trophoblasts and monocytes. Int Immunol (1999) 11(5):803-11. doi:10.1093/intimm/11.5.803

86. Cha J, Sun X, Dey SK. Mechanisms of implantation: strategies for successful pregnancy. Nat Med (2012) 18(12):1754-67. doi:10.1038/nm.3012

87. Morimoto RI, Santoro MG. Stress-inducible responses and heat shock proteins: new pharmacologic targets for cytoprotection. Nat Biotechnol (1998) 16(9):833-8. doi:10.1038/nbt0998-833

88. Voss AK, Thomas T, Gruss P. Mice lacking HSP90beta fail to develop a placental labyrinth. Development (2000) 127(1):1-11.

89. Brosens JJ, Salker MS, Teklenburg G, Nautiyal J, Salter S, Lucas ES, et al. Uterine selection of human embryos at implantation. Sci Rep (2014) 4:3894. doi:10.1038/srep03894

90. Calderwood SK, Mambula SS, Gray PJ Jr, Theriault JR. Extracellular heat shock proteins in cell signaling. FEBS Lett (2007) 581(19):3689-94. doi:10.1016/j. febslet.2007.04.044

91. Matzinger P. The danger model: a renewed sense of self. Science (2002) 296(5566):301-5. doi:10.1126/science.1071059

92. Hayoun D, Kapp T, Edri-Brami M, Ventura T, Cohen M, Avidan A, et al. HSP60 is transported through the secretory pathway of 3-MCA-induced fibrosarcoma tumour cells and undergoes N-glycosylation. FEBS J (2012) 279(12):2083-95. doi:10.1111/j.1742-4658.2012.08594.x

93. Hightower LE, Guidon PT Jr. Selective release from cultured mammalian cells of heat-shock (stress) proteins that resemble glia-axon transfer proteins. J Cell Physiol (1989) 138(2):257-66. doi:10.1002/jcp.1041380206

94. Mansilla MJ, Costa C, Eixarch H, Tepavcevic V, Castillo M, Martin R, et al. Hsp70 regulates immune response in experimental autoimmune encephalomyelitis. PLoS One (2014) 9(8):e105737. doi:10.1371/journal.pone. 0105737

95. Multhoff G. Activation of natural killer cells by heat shock protein 70. Int J Hyperthermia (2002) 18(6):576-85. doi:10.1080/0265673021000017109

96. van Eden W, van der Zee R, Prakken B. Heat-shock proteins induce T-cell regulation of chronic inflammation. Nat Rev Immunol (2005) 5(4):318-30. doi: $10.1038 /$ nri1593
97. Ibrahim EC, Morange M, Dausset J, Carosella ED, Paul P. Heat shock and arsenite induce expression of the nonclassical class I histocompatibility HLA-G gene in tumor cell lines. Cell Stress Chaperones (2000) 5(3):207-18. doi:10.1379/1466-1268(2000)005<0207:HSAAIE > 2.0.CO;2

98. Xiao X, Zuo X, Davis AA, McMillan DR, Curry BB, Richardson JA, et al. HSF1 is required for extra-embryonic development, postnatal growth and protection during inflammatory responses in mice. EMBO J (1999) 18(21):5943-52. doi:10.1093/emboj/18.21.5943

99. Shkoda A, Ruiz PA, Daniel H, Kim SC, Rogler G, Sartor RB, et al. Interleukin-10 blocked endoplasmic reticulum stress in intestinal epithelial cells: impact on chronic inflammation. Gastroenterology (2007) 132(1):190-207. doi:10.1053/ j.gastro.2006.10.030

100. Hasnain SZ, Tauro S, Das I, Tong H, Chen AC, Jeffery PL, et al. IL-10 promotes production of intestinal mucus by suppressing protein misfolding and endoplasmic reticulum stress in goblet cells. Gastroenterology (2013) 144(2):357-368e9. doi:10.1053/j.gastro.2012.10.043

101. Cheng SB, Sharma S. Interleukin-10: a pleiotropic regulator in pregnancy. Am J Reprod Immunol (2014). doi:10.1111/aji.12329

102. Ghosh R, Lipson KL, Sargent KE, Mercurio AM, Hunt JS, Ron D, et al. Transcriptional regulation of VEGF-A by the unfolded protein response pathway. PLoS One (2010) 5(3):e9575. doi:10.1371/journal.pone.0009575

Conflict of Interest Statement: The authors declare that the research was conducted in the absence of any commercial or financial relationships that could be construed as a potential conflict of interest.

Received: 22 December 2014; accepted: 09 March 2015; published online: 30 March 2015.

Citation: Gregori S, Amodio G, Quattrone F and Panina-Bordignon P (2015) HLA-G orchestrates the early interaction of human trophoblasts with the maternal niche. Front. Immunol. 6:128. doi: 10.3389/fimmu.2015.00128

This article was submitted to Immunological Tolerance, a section of the journal Frontiers in Immunology.

Copyright $\odot 2015$ Gregori, Amodio, Quattrone and Panina-Bordignon. This is an open-access article distributed under the terms of the Creative Commons Attribution License (CC BY). The use, distribution or reproduction in other forums is permitted, provided the original author(s) or licensor are credited and that the original publication in this journal is cited, in accordance with accepted academic practice. No use, distribution or reproduction is permitted which does not comply with these terms. 